\title{
Surgical Infections: A Microbiological Study
}

\author{
Santosh Saini ${ }^{1}$, Naveen Gupta ${ }^{1}$, Aparna ${ }^{1}$, \\ Lokveer $^{1}$ and M.S. Griwan ${ }^{2}$
}

\author{
Department of Microbiology, Department of \\ Surgery ${ }^{2}$, Pt. B.D. Sharma PGIMS, Rohtak, India
}

\begin{abstract}
Surgical infections are mostly polymicrobial, involving both aerobes and anaerobes. One hundred seventeen cases comprised of abscesses $(n=51)$, secondary peritonitis $(n=25)$, necrotizing fascitis $(n=22)$ and wounds with devitalized tissues $(n=19)$ were studied. The number of microorganisms isolated per lesion was highest in secondary peritonitis (2.32). The aerobe/ anaerobe ratio was 0.81 in secondary peritonitis and 1.8 in necrotizing fascitis. Most secondary peritonitis $(80 \%)$, necrotizing fascitis $(75 \%)$ and wounds with devitalized tissues $(66.7 \%)$ were polymicrobial. Common microorganisms isolated in our study were E. coli, Staphylococcus aureus, Klebsiella spp., Pseudomonas aeruginosa, Bacteroides fragilis and Peptostreptococcus spp. The most effective antibiotics for $S$. aureus were clindamycin $(\mathbf{7 9 . 1 \%})$ and cefuroxime $\mathbf{( 7 0 . 8 \% )}$. For Gram-negatives (Klebsiella spp., $E$. coli and Proteus spp.), the most effective antibiotics were cefotaxime, ceftizoxime, amikacin and ciprofloxacin. Pseudomonas aeruginosa was maximally sensitive to amikacin (35.2\%) and ciprofloxacin $(35.2 \%)$. The greatest degree of multidrug resistance to all the drugs was found in P. aeruginosa $(52.9 \%)$, followed by Klebsiella spp. $(33.3 \%)$, Proteus spp. $(33.3 \%)$, E. coli $(22.2 \%)$, and $S$. aureus $(12.5 \%)$. All the anaerobes that we isolated were $100 \%$ sensitive to metronidazole and chloramphenicol, followed by clindamycin $(95 \%$ to $100 \%)$. Apart from antibiotic therapy, non-antimicrobial methods, such as hyperbaric oxygen therapy and debridement also play an important role in the treatment of surgical infections. Key Words: Abscess, secondary peritonitis, necrotizing fascitis and wounds with devitalized tissue.
\end{abstract}

The microbiology laboratory plays a key role in providing information about surgical infections that slowly worsen or otherwise fail to heal. The main pathogens or groups of microorganisms that a microbiology laboratory should routinely detect and report (with antibiograms being provided when appropriate) are as follows: Staphylococcus aureus, Pseudomonas aeruginosa, beta hemolytic streptococci, coliform bacteria, pigmented Gramnegative anaerobes (Prevotella and Porphyromonas spp.) non - pigmented Gram-negative anaerobes

Received on 15 October 2003; revised 24 March 2004.

Address for correspondence: Dr. Naveen Gupta. Department of Microbiology, Pt. B.D. Sharma Post Graduate, Institute of Medical Sciences, Rohtak (Haryana), India. E-mail: micronaveen@hotmail.com

The Brazilian Journal of Infectious Diseases 2004;8(2):118-125 (C) 2004 by The Brazilian Journal of Infectious Diseases and Contexto Publishing. All rights reserved. (primarily Bacteroides, Prevotella and Fusobacterium spp.), Peptostreptococcus spp., and Clostridium spp. [1].

The introduction of microorganisms into a previously sterile site, such as a wound, is termed contamination. Many contaminating bacteria find the tissues of the wound a hostile environment and succumb. Other species that are able to survive begin to actively multiply and the wound may be said to have been colonized. Colonization does not always lead to infection. Which of the colonizing bacterial species eventually emerge as actual etiological agents of infection depends upon their virulence, relative numbers, and on selective factors, such as wound environment and antibiotics. The bacterial flora of the open wound is seldom static; it is usually changing, new organisms appear in wounds and old ones disappear [2].

The effect of specific types of microorganisms on wound healing has been extensively studied; mostly they 
are polymicrobial, involving both aerobes and anaerobes. These pathogens cause delayed healing and infection [1]. We investigated the role of anaerobes and aerobes in abscesses, secondary peritonitis, necrotising fascitis, and in wounds with devitalized tissue, to determine the optimal antimicrobial therapy.

\section{Material and Methods}

The investigation was conducted at PGIMS, Rohtak from July 2001 and June 2002. The study group included:

(a) Abscess group (Group A) - having closed abscesses (single/multiple) with redness and brownish induration at the periphery.

(b) Secondary peritonitis (Group B) - patients from the emergency operation room who had signs and symptoms of peritonitis.

(c) Necrotising fascitis (Group C) - patients having unexplained fever with pain, brownish edema, tenderness and brownish grey interfascial planes.

(d) Wounds with devitalized tissue (Group D) gangrenous tissue with no sensation, no blood supply, blackening of the affected organ or portion, and foul odor coming from the affected part.

\section{Specimen collection}

Skin or mucus membranes were decontaminated using alcohol or povidone iodine. The specimens were purulent exudate aspirated from abscesses, peritoneal fluid or exudate from peritonitis, swab, exudate or aspirate from deep necrotising fascitis and devitalized gangrenous tissue. For anaerobic culture, the specimens were collected in cooked meat broth $(\mathrm{CMB}, \mathrm{Hi}-$ Media) and incubated at $37^{\circ} \mathrm{C}$ for 48 hours. The media used for aerobic incubation were $5 \%$ sheep blood agar, MacConkey agar, 7\% salt agar and chocolate agar. Chocolate agar was incubated aerobically with $5 \%$ to $10 \% \mathrm{CO}_{2}$. The media used for anaerobic incubation were Brain Heart Infusion agar (BHI), neomycin BHI agar, Bacteroides Bile esculin agar. Anaerobic incubation was done with $P$. aeruginosa as a biological indicator and alkaline methylene blue glucose as a chemical indicator.

Aerobes were identified using standard microbiological methods [3] and anaerobes were processed for identification up to level III as per the Wadsworth Anaerobic Bacteriology Manual [4]. Various commonly used antimicrobial agents that are recommended by NCCLS were used to ascertain the susceptibility pattern of aerobes and anaerobes by the disc diffusion method [5]. Reference strain $S$. aureus NCTC 6571 was used as a control for Gram-positive cocci, E. coli NCTC 10418 for Gram-negative bacilli, and $P$. aeruginosa NCTC 10662 for Pseudomonas.

\section{Results}

One hundred seventeen cases were included, among which 51 were closed abscesses (Group A), 25 were secondary peritonitis (Group B), 22 were necrotizing fascitis (Group C) and 19 wounds had devitalized tissue (Group D). Out of these, 17 (14.5\%) were sterile. Culture positivity in groups A, B, C and D was $78.4 \%, 100 \%, 90.9 \%$ and $79 \%$, respectively. The number of organisms isolated per lesion was highest in group B (2.32), followed by group C (2.1), Group A (1.45) and group $\mathrm{D}$ (1.4). The polymicrobial nature of infection was greatest in group B $(80 \%)$, followed by group C (75\%), group D (66.7\%) and group A (35\%). The distribution of aerobes and anaerobes in monomicrobial and polymicrobial infections was determined (Table 1). Aerobes alone were the most common causes of infection in groups A (87.5\%) and $\mathrm{D}(53.3 \%)$, whereas mixed aerobes and anaerobes were encountered in $72 \%$ of group B cases and $60 \%$ of group $\mathrm{C}$ cases. The aerobe/anaerobe ratio was highest in group A (10.6), followed by group D (2.0), group C (1.8), and lowest in group B (0.8). Fifty-eight microorganisms were isolated from group A infections $(\mathrm{n}=40), 53(91.3 \%)$ of which were aerobes. Among the aerobes, $S$. aureus, and $E$. coli were predominant. Fifty-eight organisms were isolated from group B infections $(n=25), 32(55.1 \%)$ of which were anaerobes and $26(44.8 \%)$ were aerobes. Bacteroides fragilis 
Table 1. Analysis of isolates from surgical infections

\begin{tabular}{|c|c|c|c|c|}
\hline & $\begin{array}{l}\text { Abscess } \\
\text { Group A }\end{array}$ & $\begin{array}{l}\text { Secondary } \\
\text { peritonitis } \\
\text { Group B }\end{array}$ & $\begin{array}{l}\text { Necrotizing } \\
\text { fascitis } \\
\text { Group C }\end{array}$ & $\begin{array}{l}\text { Wounds with } \\
\text { devitalized tissue } \\
\text { Group D }\end{array}$ \\
\hline Total number of patients & 51 & 25 & 22 & 19 \\
\hline Sterile & $11(21.6 \%)$ & $0(0.0 \%)$ & $2(9.1 \%)$ & $4(21 \%)$ \\
\hline Culture positive & $40(78 \%)$ & $25(100 \%)$ & $20(91 \%)$ & $15(79 \%)$ \\
\hline Number of isolates & 58 & 58 & 42 & 21 \\
\hline Organism rate per lesion & 1.45 & 2.32 & 2.1 & 1.4 \\
\hline Only aerobes & $35(87.5 \%)$ & $3(12 \%)$ & $7(35 \%)$ & $8(53 \%)$ \\
\hline Only anaerobes & $2(5 \%)$ & $4(16 \%)$ & $1(5 \%)$ & $3(20 \%)$ \\
\hline Aerobes + Anaerobes & $3(7.5 \%)$ & $18(72 \%)$ & $12(60 \%)$ & $4(27 \%)$ \\
\hline Aerobe/anaerobe ratio & 10.6 & 0.81 & 1.8 & 2.0 \\
\hline Monomicrobial & $26(65 \%)$ & $5(20 \%)$ & $5(25 \%)$ & $5(33 \%)$ \\
\hline Aerobes & $24(92.3 \%)$ & $2(40 \%)$ & $4(80 \%)$ & $3(60 \%)$ \\
\hline Anaerobes & $2(7.7 \%)$ & $3(60 \%)$ & $1(20 \%)$ & $2(40 \%)$ \\
\hline Polymicrobial & $14(35 \%)$ & $20(80 \%)$ & $15(75 \%)$ & $10(67 \%)$ \\
\hline 2 aerobes & $8(57 \%)$ & $1(5 \%)$ & $2(5 \%)$ & $2(20 \%)$ \\
\hline 3 aerobes & $3(21.4 \%)$ & - & $1(6.7 \%)$ & - \\
\hline 2 anaerobes & - & $1(5 \%)$ & - & - \\
\hline 1 aerobe +1 anaerobe & - & $6(30 \%)$ & $1(6.6 \%)$ & - \\
\hline 1 aerobe +2 anaerobes & $1(7.1 \%)$ & $1(5 \%)$ & $3(20 \%)$ & $2(20 \%)$ \\
\hline 2 aerobes +1 anaerobe & $2(4.3 \%)$ & $8(40 \%)$ & $7(46.6 \%)$ & $6(60 \%)$ \\
\hline 2 aerobes +2 anaerobes & - & $3(15 \%)$ & $1(6.6 \%)$ & - \\
\hline
\end{tabular}

and Peptostreptococcus anaerobius were predominant among the anaerobes, whereas among the aerobes, E. coli and Klebsiella spp. were predominant in group B infections. In group C $(n=22), 42$ microorganisms were isolated, $27(64.2 \%)$ of which were aerobes. The predominant aerobic and anaerobic isolates were E. coli, S. aureus, Peptostreptococcus spp. and $B$. fragilis. In group D ( $\mathrm{n}=15)$ infections, 21 microorganisms were isolated, 14 (66.6\%) of which were aerobes, and the predominant microorganisms were E. coli, Klebsiella spp., Prevotella melaninogenicus and Peptostreptococcus spp.

The antibiotic susceptibility pattern of the aerobes and anaerobes was determined (Tables 3 and 4, respectively). The mosteffective antibiotics for $S$. aureus were clindamycin $(79.1 \%)$, amikacin $(70.8 \%)$, and cefuroxime $(70.8 \%)$. While, the most effective antibiotics for the Gram-negatives (K. pneumoniae, E. coli and Proteus spp.) were cefotaxime, ceftizoxime, amikacin and ciprofloxacin (Table 3). Pseudomonas aeruginosa was most sensitive to amikacin (35.2\%) and ciprofloxacin (35.2\%). The highest degree of multidrug resistance to all the drugs was found in P. aeruginosa (52.9\%), followed by Klebsiella spp. (33.3\%), Proteus spp. (33.3\%), E. coli (22.2\%), and S. aureus (12.5\%).

All the anaerobes were $100 \%$ sensitive to metronidazole and chloramphenicol, followed by clindamycin (95-100\%) (Table 4). On the other hand the anaerobes were highly resistant to penicillin and erythromycin. 
Table 2. Aerobes and anaerobes isolated in the study group

\begin{tabular}{|c|c|c|c|c|}
\hline Organism & $\begin{array}{l}\text { Group A } \\
(n=40)\end{array}$ & $\begin{array}{l}\text { Group B } \\
(n=25)\end{array}$ & $\begin{array}{l}\text { Group C } \\
(n=22)\end{array}$ & $\begin{array}{l}\text { Group D } \\
(n=15)\end{array}$ \\
\hline \multicolumn{5}{|l|}{ Aerobes } \\
\hline Gram-Positive cocci & 30 & 2 & 8 & 2 \\
\hline Staphylococcus aureus & 16 & 1 & 5 & 2 \\
\hline Coagulase negative staphylococcus & 6 & - & 2 & - \\
\hline Streptococcus pyogenes & 5 & 1 & 1 & - \\
\hline Streptococcus viridans & 3 & - & - & - \\
\hline Gram-negative bacilli & $\underline{23}$ & $\underline{24}$ & $\underline{19}$ & $\underline{12}$ \\
\hline Escherichia coli & $\overline{7}$ & $\overline{9}$ & $\overline{6}$ & $\overline{5}$ \\
\hline Klebsiella spp. & 5 & 6 & 4 & 3 \\
\hline Proteus spp. & 2 & 3 & 2 & 2 \\
\hline Pseudomonas aeruginosa & 6 & 4 & 5 & 2 \\
\hline Other non-fermenters & 3 & 2 & 2 & - \\
\hline Total aerobes & 53 & 26 & 27 & 14 \\
\hline
\end{tabular}

\section{Anaerobes}

Gram-positive cocci 3

Peptostreptococcus anaerobius 1

Peptostreptococcus asaccharolytic

Gram-negative cocci

Veillonella spp.

Gram-positive bacilli

Eubacterium spp.

Bifidobacterium spp.

Lactobacillus

\section{Gram-negative bacilli}

Bacteroides fragilis

Prevotella melaninogenicus

Fusobacterium spp.

Mobiluncus spp.

3

7

2

12

- 3$$
3
$$

118

3

3

$-14$

- 1

13

142

$\begin{array}{ll}14 & 3\end{array}$

3

Total anaerobes 
Table 3. Sensitivity pattern of common aerobic isolates from surgical infections

\begin{tabular}{|c|c|c|c|c|c|}
\hline & $\begin{array}{l}\text { S. aureus } \\
(\mathrm{n}=24)\end{array}$ & $\begin{array}{l}\text { K. pneumoniae } \\
(\mathrm{n}=18)\end{array}$ & $\begin{array}{l}\text { P. aeruginosa } \\
(\mathrm{n}=17)\end{array}$ & $\begin{array}{l}\text { E. coli } \\
(\mathrm{n}=27)\end{array}$ & $\begin{array}{l}\text { Proteus spp. } \\
(\mathrm{n}=9)\end{array}$ \\
\hline $\begin{array}{l}\text { Amikacin } \\
(10 \mu \mathrm{g})\end{array}$ & $17(70.8 \%)$ & $10(55.5 \%)$ & $6(35.2 \%)$ & $20(74 \%)$ & $4(44.4 \%)$ \\
\hline $\begin{array}{l}\text { Ampicillin } \\
(10 \mu \mathrm{g})\end{array}$ & - & $1(5.5 \%)$ & - & $1(3.7 \%)$ & $1(11.1 \%)$ \\
\hline $\begin{array}{l}\text { Cefotaxime } \\
(10 \mu \mathrm{g})\end{array}$ & - & $15(83.3 \%)$ & $4(23.5 \%)$ & $18(66.6 \%)$ & $7(77.7 \%)$ \\
\hline $\begin{array}{l}\text { Ceftazidime } \\
(10 \mu \mathrm{g})\end{array}$ & - & - & $2(11.7 \%)$ & - & - \\
\hline $\begin{array}{l}\text { Ceftizoxime } \\
(30 \mu \mathrm{g})\end{array}$ & - & $15(83.3 \%)$ & $6(35.2 \%)$ & $21(77.7 \%)$ & $5(55.5 \%)$ \\
\hline $\begin{array}{l}\text { Cefuroxime } \\
(30 \mu \mathrm{g})\end{array}$ & $17(70.8 \%)$ & $2(11.1 \%)$ & - & $3(11.1 \%)$ & $2(22.2 \%)$ \\
\hline $\begin{array}{l}\text { Clindamycin } \\
(2 \mu \mathrm{g})\end{array}$ & $19(79.1 \%)$ & - & - & - & - \\
\hline $\begin{array}{l}\text { Co-trimoxazole } \\
(25 \mu \mathrm{g})\end{array}$ & $3(12.5 \%)$ & $1(5.5 \%)$ & - & $1(3.7 \%)$ & $0.0 \%$ \\
\hline $\begin{array}{l}\text { Ciprofloxacin } \\
(10 \mu \mathrm{g})\end{array}$ & - & $9(50.0 \%)$ & $6(35.2 \%)$ & $14(51.8 \%)$ & $4(44.4 \%)$ \\
\hline $\begin{array}{l}\text { Erythromycin } \\
(10 \mu \mathrm{g})\end{array}$ & $15(62.5 \%)$ & - & - & - & - \\
\hline $\begin{array}{l}\text { Gentamicin } \\
(10 \mu \mathrm{g})\end{array}$ & - & $3(16.6 \%)$ & $2(11.7 \%)$ & $5(18.5 \%)$ & $1(11.1 \%)$ \\
\hline $\begin{array}{l}\text { Norfloxacin } \\
(10 \mu \mathrm{g})\end{array}$ & - & $3(16.6 \%)$ & - & $3(11.1 \%)$ & $1(11.1 \%)$ \\
\hline $\begin{array}{l}\text { Penicillin } \\
(2 \mathrm{IU})\end{array}$ & $5(20.8 \%)$ & - & - & - & - \\
\hline $\begin{array}{l}\text { Piperacillin } \\
(100 \mu \mathrm{g})\end{array}$ & - & - & $2(11.7 \%)$ & - & - \\
\hline $\begin{array}{l}\text { Tetracycline } \\
(10 \mu \mathrm{g})\end{array}$ & $7(29.1 \%)$ & $2(11.1 \%)$ & - & $3(11.1 \%)$ & $1(11.1 \%)$ \\
\hline
\end{tabular}

Table 4. Susceptibility pattern of anaerobic isolates from surgical infectionsism

\begin{tabular}{lllll}
\hline Organism & GPC $(\mathbf{n = 2 1})$ & GNC $(\mathbf{n = 4})$ & GPB $(\mathbf{n = 9})$ & GNB $(\mathbf{n = 2 5})$ \\
\hline Metronidazole $(5 \mu \mathrm{g})$ & 21 & 4 & 9 & 25 \\
Penicillin $(2 \mathrm{IU})$ & 15 & 3 & 6 & 7 \\
Clindamycin $(2 \mu \mathrm{g})$ & 20 & 4 & 9 & 24 \\
Cefuroxime $(30 \mu \mathrm{g})$ & 16 & 4 & 8 & 14 \\
Chloramphenicol $(10 \mu \mathrm{g})$ & 21 & 4 & 9 & 25 \\
Erythromicin $(10 \mu \mathrm{g})$ & 10 & 2 & 6 & 9 \\
Cefotaxime $(30 \mu \mathrm{g})$ & 17 & 4 & 9 & 22 \\
\hline
\end{tabular}

GPC $=$ Gram-positive cocci, GNC = Gram-negative cocci. GPB = Gram-positive bacilli, GNB = Gram-negative bacilli. 


\section{Discussion}

Surgical infections, such as abscesses, secondary peritonitis, necrotising fascitis and wounds with devitalized tissues are largely polymicrobial, and the role of both aerobic and anaerobic bacteria in the pathogenesis of these infections is well recogniszed. Microbial synergy may increase the net pathogenic effect and hence the severity of infection in several ways: (i) oxygen consumption by aerobic bacteria induces tissue hypoxia and a lowering of the redox potential, which favors the growth of anaerobic bacteria; (ii) specific nutrients produced by one bacterium may encourage the growth of fastidious and potentially pathogenic cohabiting microorganisms; and (iii) some anaerobes are able to impair host immune cell function and thus provide a competitive advantage for themselves as well as for other, cohabiting, microorganisms [1].

An abscess is a localized collection of purulent inflammatory tissue caused by suppuration deep within a tissue, an organ or a confined space. It is produced by deep seeding of pyogenic bacteria into a tissue. It may involve skin, dermis, fasciae, muscles, and even bones. Abscess inside the cavities poses a great problem for treatment, e.g. brain abscess, pleural abscess, and intra-abdominal abscess [6]. Among our group A ( $\mathrm{n}=51)$ infections, 11 (21.6\%) were sterile. The mean number of species of organisms per lesion was 1.45 and the aerobe/anaerobe ratio was 10.6; 65\% of the infections were monomicrobial. Staphylococcus aureus and E. coli were the predominant aerobes, while Peptostreptococci were common among the anaerobes. Wren reported Bacteroides spp. (40.4\%), Fusobacterium (10.1\%), Clostridium spp. (2.2\%), gram-positive non-sporulating bacilli (13.4\%) and Veillonella spp. (5.6\%), from pus samples aspirated from closed abscesses or pus-filled cavities [7]. Brook reported in 1995 that Bacteroides spp. (32\%) is the most common bacteria in abscesses, followed by $E$. coli and Peptostreptococcus spp. [8]. Sunmonen et al. studied 86 abscesses in intravenous drug users (IVDU); these yielded 173 aerobes and 131 anaerobes, among which $S$. aureus was most common (50\%), while among the anaerobes, Prevotella spp.,
F. nucleatum, P. micros, A. odontolyticus and Veillonella were isolated. In non IVDU, S. aureus was the most common (53\%), followed by coagulasenegative staphylococcus (CONS) (19\%), Streptococcus millieri and Streptococcus pyogenes. The main anaerobes isolated were Peptostreptococcus spp., Bacteroides spp. and Gram-positive bacilli [9].

Peritonitis is a localized or generalized inflammatory process of the peritoneum, which may appear in both acute and chronic forms. In the acute form, the motor activity of the intestine is decreased and the intestinal lumen becomes distended with gas and fluid. Secondary peritonitis may be due to the entry of bacilli into the peritoneal cavity through perforations of the gut or from an external penetrating wound. The most common causes of secondary peritonitis are appendicitis, perforations associated with diverticulitis, peptic ulcer, gangrenous gall bladder and gangrenous obstructions of the small bowel from adhesive bands, incarcerated hernia or volvulus [10]. In study group B, a mean of 2.32 organisms were isolated per lesion, with both aerobes and anaerobes in $72 \%$ of the cases, and an aerobe/anaerobe ratio of 0.81 . Eighty percent of the group B infections were polymicrobial, among which E. coli, Klebsiella spp., and P. aeruginosa were the most common aerobes, while B. fragilis, Peptostreptococcus spp. were common among the anaerobes. Other researchers have reported $E$. coli, Klebsiella spp., B. fragilis, Peptostreptococcus spp. in intra-abdominal infections, in accordance with our findings [11,12].

Necrotising fascitis, formerly called streptococcal gangrene, may be associated with group A streptococci or mixed aerobic and anaerobic bacteria. Necrotizing fascitis is comprised of the following signs and symptoms: (a) pain and unexplained fever, (b) swelling, brawny edema, tenderness, (c) dark red induration of the epidermis, bullae filled with blue or purple fluid, (d) thrombosis of blood vessels, and (e) extension of infection along fascial planes [13]. In our study group, $\mathrm{C}$ infections were $75 \%$ polymicrobial in nature, comprising $2 \%$ of the organisms isolated per lesion and an aerobe/ anaerobe ratio of 1.8. Common aerobes in our study were $S$. aureus, E. coli, CONS, $P$. 
aeruginosa and Klebsiella spp., while Peptostreptoccocus spp. and Bacteroides spp. were common anaerobes. Giuliano et al. reported 124 isolates detected from 15 patients with similar sources of isolates [14]. Perra and Howard reported an average of 3.5 organisms isolated per patient, among which Staphylococcus spp., group D streptococci, Pseudomonas, S. viridans, and Proteus mirabilis were common aerobes, while among anaerobes Bacteroides spp., Peptostreptococcus spp. and $C$. perfringens were predominant [15]. Other researchers have reported similar results $[16,17]$.

Wounds and devitalized tissues are characterized by rapidly spreading edema, myositis, tissue necrosis, gas production, and profound toxaemia, occurring as a complication of wound infection. Infection usually results from contamination of the wound with soil, particularly that from cultivated land. It may be indirectly derived from dirty clothing, street dust and even the air of a poorly ventilated theatre [18]. In our study, $66.7 \%$ of the group D infections were polymicrobial and 1.4 organisms were isolated per lesion, with an aerobe/anaerobe ratio of 2.0. The most common aerobes isolated in our study were $E$. coli, Klebsiella, S. aureus and Proteus spp., while the most common anaerobes were Peptostreptococcus spp. and $P$. melaninogenicus. Baradkar et al., who made a study of 63 clinically suspected cases of gangrene, found that $82.5 \%$ of the samples yielded both aerobes and anaerobes. In their study E. coli (38.4\%) emerged as the most common pathogen, followed by Proteus spp. (12.8\%), Klebsiella spp. (35.8\%) and S. aureus (12.8\%), while among the anaerobes, Clostridium spp. and Peptostreptococci were predominant [19].

Today it is clear that there is significant problem with increasing resistance to antimicrobial agents among anaerobic bacteria. Multiple mechanisms of resistance have been encountered in anaerobes, as well as in aerobes [20], e.g. $\beta$-lactam is the enzyme responsible for inactivating the $\beta$-lactam ring of $\beta$-lactam antibiotics in both Gram-positives and Gram-negatives, whereas loss of the outer membrane protein and altered target sites are mechanisms of resistance in Bacteroides spp. [21]. We found that culturing and determining the sensitivity of aerobes and anaerobes is of the utmost importance in cases of abscesses, secondary peritonitis, necrotising fascitis and wounds with devitalized tissues. We recommend the use of metronidazole, chloramphenicol or clindamycin for the treatment of anaerobic infections and third generation cephalosporins, amikacin and ciprofloxacin for Gramnegative aerobes and clindamycin or cefuroxime for $S$. aureus. The choice of prophylactic antibiotics should cover both facultatively anaerobic and anaerobic bacteria, with high concentrations during surgery and throughout the duration of the surgical procedures. Newer classes of antibiotics, such as ureidopenicillin, carbapeneous and the $\beta$-lactam $/ \beta$-lactamase inhibitor combinations, has expanded the choice for both prophylactic and therapeutic treatment. Combination therapy with an aminoglycoside (e.g. amikacin) or a cephalosporin (cefotaxime or ceftizoxime), plus clindamycin or metronidazole, is very effective. Apart from antibiotic therapy, nonantimicrobial methods, such as hyperbaric oxygen therapy, and debridement also play an important role in the treatment of surgical infections.

\section{References}

1. Bowler P.G., Duerden B.I., Armstrong D.G.. Wound microbiology and associated approaches to wound management. Clin Microbiol Rev 2001;244-69.

2. Ellner P.D. Microbiology of wounds. In: Lorian V, editor. Significance of Medical Microbiology. 2nd ed. Baltimore: Williams \& Wilkins; 1982:158-68.

3. Koneman E.W., Allen S.D., Janda W.M., et al. Colour Atlas and Textbook of Diagnostic Microbiology. 5th ed. USA: Lippincott, 1997.

4. Sutter V.L., Citron D.M., Edelstein M.A.C., Finegold S.M. Processing of clinical specimens and isolation and identification procedures. In: Wadsworth Anaerobic Bacteriology Manual. 4th ed. Belmont: Star Publishing; 1985:23-70.

5. National Committee for Clinical Laboratory Standards (NCCLS). Performance Standards for Antimicrobial Susceptibility Testing. Sixth ed., Approved Standards M2-A6, 1997: Wayne, Pennsylvania.

6. Tucker C. Acute and chronic inflammation. In: Cotran, Kumar, Collins, Robbins's Pathologic Basis of Disease. 6th ed. Philadelphia: WB Saunders Co.; 1999:50-89. 
7. Wren M.W.D. The culture of clinical specimen for anaerobic bacteria: a comparison of three regimen. J Med Microbiol 1977; 10:195-201.

8. Brook I.. Bacteroides infections in children. J Med Microbiol 1995;43:92-8.

9. Summanen P.H., Talan D.A., Strong C., et al. Bacteriology of skin and soft tissue infections: Comparison of infections in intravenous drug users and individuals with no history of intravenous drug use. Clin Infect Dis 1995;20(2):S279-82.

10. Isselbacher K.J., Epstein A. Diverticular, vascular and other disorders of intestine and peritoneum. In: Fauci A.S., Braunwald E., Isselbacher K.J., et al. [editors]. Harrison's Principles of Internal Medicine. 14th ed. New York: McGraw Hill; 1998: 1648-56.

11. Gorbach S.L., Norsen J. Anaerobic microorganisms in intraabdominal infections. In: Balows A, Dehaan RH, Dowell VR Jr. editors. Anaerobic bacteria: Role in Disease. Springfield: Charles C. Thomas; 1974:212-38.

12. Swenson R.M., Lorber B., Michaelson T.C. The bacteriology of intraabdominal infections. Arch Surg 1974;109:398.

13. Stevens D.L. Infections of the skin, muscle and soft tissues. In: Fauci AS, Braun WE, Isselbacher KJ, Wilson JD, Martin JB, Kasper DL et al editors. Harrison's Principles of Internal Medicine. 14th ed. New York: McGraw Hill; 1998:827-30.

14. Guiliano A., Lewis F., Hadley K., Blaisdell F.W. Bacteriology of necrotizing fascitis. Am J Surg 1977;134:52-7.

15. Perra M.E., Howard R.J. Necrotizing fascitis. Surg Gynecol Obstet 1985; 161:357-61.

16. Brook I., Frazier E.H. Clinical and microbiological features of necrotizing fascitis. J Clin Microbiol 1995;33(9):2382-7.

17. Anuradha D., Biswas J., Saraswathi K., Gogate A.Microbiological features of necrotising fascitis. Ind J Med Microbiol 1999; 17(1):18-21.

18. Colle J.G. Clostridium: gas gangrene, tetanus, food poisoning, pseudomembranous colitis. In: Greenwood D, Slack R, Pentherer J, editors. Medical Microbiology. 15th ed. London: Churchill Livingston; 1998:232-42.

19. Banadkar V.P., Patwardhan N.S., Deshmukh A.B., et al. Bacteriological study of clinically suspected cases of gas gangrene. Ind J Med Microbiol 1999;17(3):133-4.

20. Bawdon R.E., Crune L.R., Palchaudhary S. Antibiotic resistance in anaerobic bacteria: molecular biology and clinical aspects. Rev Infect Dis 1982;4:1075-95.

21. Chaudhary R., Mazumdar J., Dhawan B. Genus Bacteroides - New concepts in pathogenesis and drug resistance. Ind J Med Microbiol 1997;15(3):107-11. 